\title{
Corela
}

Cognition, représentation, langage

3-2 | 2005

Vol. $3, n^{\circ} 2$

\section{Family resemblances and the structure of spatial relationships}

\section{Claude Vandeloise}

\section{(2) OpenEdition}

\section{Journals}

\section{Electronic version}

URL: http://journals.openedition.org/corela/514

DOI: 10.4000/corela.514

ISSN: 1638-573X

\section{Publisher}

Cercle linguistique du Centre et de I'Ouest - CerLICO

Electronic reference

Claude Vandeloise, "Family resemblances and the structure of spatial relationships », Corela [Online], 3-2 | 2005, Online since 27 December 2005, connection on 19 April 2019. URL : http:// journals.openedition.org/corela/514; DOI : 10.4000/corela.514

This text was automatically generated on 19 April 2019

\section{(c) (i) (3) (-)}

Corela - cognition, représentation, langage est mis à disposition selon les termes de la licence Creative Commons Attribution - Pas d'Utilisation Commerciale - Partage dans les Mêmes Conditions 4.0 International. 


\title{
Family resemblances and the structure of spatial relationships
}

\author{
Claude Vandeloise
}

The notion of family resemblance features or traits was first introduced by Wittgenstein (1953) with the category game. According to the more extreme interpretation of family resemblances, no member in a family possesses all the traits shared by the members of the family and no trait of the family is shared by all the members. As a consequence, two members in a family resemblance category do not have to share a single trait in order to be in the same category. This structure is represented in figure 1, in which the circles represent the extensions of the members of a family resemblance category satisfying a trait (a), a trait (b) and a trait (c) respectively:

Figure 1

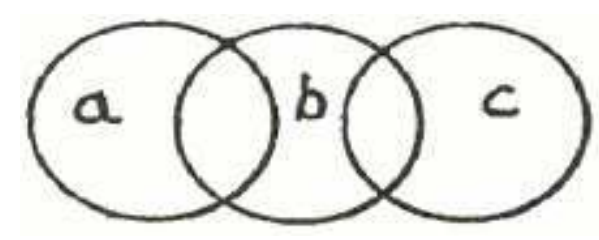

Figure 2

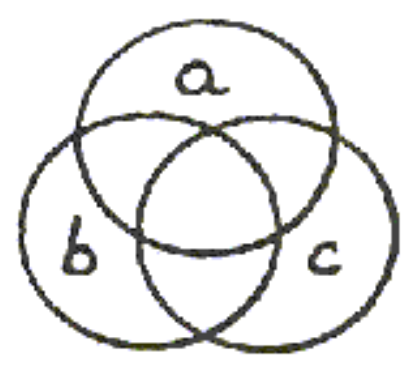


2 This extremely loose structure would fit perfectly Wittgenstein's intention since the philosopher wanted to demonstrate that a word is not explained by a further mysterious entity called meaning but is directly justified by its use in language-games. By a strange twist to Wittgenstein's negative use of family resemblances, Rosch and her colleagues (Rosch and Mervis 1975, Rosch et al. 1976) happened to use this concept as a positive tool in important research into human categorization. This positive role of family resemblance categories is made possible because, in contrast to the model represented in figure 1, many natural categories studied by Rosch have an important core of prototypical members sharing all the traits of the category, as in figure 2 in which the members in the intersection satisfy traits (a), (b) and (c).

3 In psychology, family resemblance features have been discussed most frequently for natural species such as animal, dog, etc. and, more conveniently, for artificial categories (Posner and Keele [1968, 1970], Rosch et al. [1976]). In linguistics, in contrast, family resemblance categories have been abundantly used in the analysis of prepositions describing spatial relationships (Vandeloise 1986, Cuyckens 1994). Without any doubt, the loose structure of family resemblance categories applies better than rigid classical categories to the flexibility of prepositions. However, as we noticed for family resemblance categories represented by figure 1 , their structure may be so loose that it goes beyond control. The purpose of this paper is to clarify as much as possible the connection between family resemblance features and the spatial lexical categories they describe. The analyses of $x$ est sur $y$ ( $x$ is on $y$ ) and of $x$ pend à $y$ ( $x$ hangs from $y$ ) are chosen to investigate this connection. The former sentence conveys primarily spatial configurations $^{1}$ of support and its extension is described in Vandeloise (1999) by family resemblance features. The set of these features and their combinations is called family resemblance bearer/burden $(B / b)$. The latter sentence conveys primarily spatial configurations of suspension and its extension is described in Vandeloise (1989). The set of family resemblance features and their combinations is called family resemblance of suspension (S). Like in figure 2, there is an important core of prototypical configurations that meet all the traits of the family resemblances $\mathrm{B} / \mathrm{b}$ and $\mathrm{S}$.

4 In the first section of this article, I summarize my analysis of the linguistic forms être sur and pendre $\grave{a}$, described by the family resemblances B/b and S. Dimensions (Garner 1978), by means of which spatial configurations are characterized by different values, make the comparison of the configurations described by $x$ est sur $y$ and $x$ pend $a$ $y$ easier than do traits. In section 2 , all the combinations of values characterizing support and suspension are considered systematically. The combinations corresponding to the configurations linguistically described by $x$ est sur $y$ and $x$ pend à $y$ determine the extension of the family resemblances $\mathrm{B} / \mathrm{b}$ and $\mathrm{S}$. This systematic investigation reveals two important aspects of the structure of family resemblances: (1) family resemblances $\mathrm{B} / \mathrm{b}$ and $\mathrm{S}$ share several values $^{2}$ and (2) all the combinations of the values of these family resemblances do not sanction membership in the categories they describe. In other words, être sur and pendre à can only be used for a subset of the combinations of the values of the family resemblances $\mathrm{B} / \mathrm{b}$ and $\mathrm{S}$. These subsets must be circumscribed if family resemblances are to provide an accurate lexical description of these expressions.

5 From a lexical point of view, the list of combinations sanctioning the use of etre sur and pendre à has the merit of proposing a representation of the extension of these expressions as exhaustive as possible. In the sequel of the article, I will leave their lexical interpretation and try to understand the role of family resemblances $\mathrm{B} / \mathrm{b}$ and $\mathrm{S}$ in the 
knowledge speakers have of these expressions. Two interpretations of family resemblances $\mathrm{B} / \mathrm{b}$ and $\mathrm{S}$ will be compared. According to the analytical interpretation, the speaker considers the traits of the family independently of what other traits may or may not be possessed by the configurations before choosing the corresponding lexical expression. In this way, family resemblances would be the last shelter for the semantic features of structuralist autonomous linguistics. According to the global interpretation of family resemblances $\mathrm{B} / \mathrm{b}$ and $\mathrm{S}$, speakers pay special attention to the overall similarity of prototypical situations of support and suspension for which all the traits of the family resemblance are gathered together ${ }^{3}$. After, they learn how the lexical expressions associated to the prototypical relationships extend to the more marginal members of the categories $\mathrm{B} / \mathrm{b}$ and $\mathrm{S}$.

6 I will argue that the structures of lexical categories such as être sur and pendre à are more in keeping with the global interpretation than with the analytical approach. Indeed, the complicated list proposed in section 2 is very unlikely to represent the knowledge speakers have of these expressions. Furthermore, this listing requires a global access to the combinations, unavailable to the analytical interpretation since, according to this latter interpretation, the selection of the members of category $\mathrm{B} / \mathrm{b}$ or $\mathrm{S}$ must be done by the traits of family resemblances $\mathrm{B} / \mathrm{b}$ and $\mathrm{S}$, considered in isolation, independently from the other traits. To reach this goal, probabilistic approaches of family resemblances are often proposed in cognitive psychology: category validities, presented in section 3 , are assigned to each trait depending on the proportion of members in each category satisfying these traits. In this way, traits common to different families receive different weights in each family. An experiment of Rosch et al. (1976) illustrates this probabilistic interpretation. However, it appears in section 4 that this solution falls short from circumscribing the subset of combinations defining the boundaries of categories $\mathrm{B} / \mathrm{b}$ and S. Consequently, no analytical interpretation of family resemblances can describe adequately the use of spatial expressions être sur and pendre à and a global interpretation in which the most prototypical configurations play a primordial role is requested.

\section{Traits of the family resemblances $B / b$ and $S$}

7 The categories $\mathrm{B} / \mathrm{b}$ and $\mathrm{S}$ are lexical categories since their extension is exclusively determined by the possibility of using the corresponding lexical expressions. For their description by family resemblances $\mathrm{B} / \mathrm{b}$ and $\mathrm{S}$, I rely on my previous analyses of support and suspension. A complete justification of the traits of the family resemblance $\mathrm{B} / \mathrm{b}$ may be found in Vandeloise $(1991,1999)$. The family resemblance $S$ is exhaustively described in Vandeloise (1989). Figures 3 and 4 represent a prototypical configuration of support and of suspension respectively. Family resemblances $\mathrm{B} / \mathrm{b}$ and $\mathrm{S}$ share many traits. Notably, for support as well as for suspension, the bearer opposes itself to the fall of the burden. However, while the opposition occurs from below in support, it occurs from above in suspension. In this case, a dependent bearer is often involved: 


\section{burden}

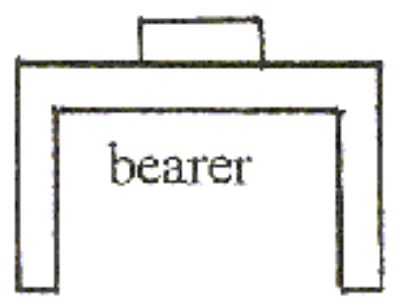

Figure 4

\section{independent bearer}

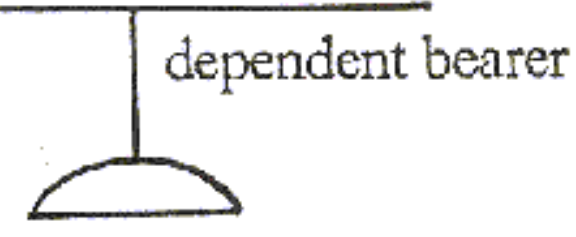

\section{burden} independent bearer. Under some conditions, a dependent bearer may be involved in support as well. As a matter of fact, the earth excepted, any bearer is dependent. Therefore, dependency is a matter of conceptualization: a bearer is dependent if, besides its relationship to the burden, its dependency on another bearer is put to the fore. Thus, according to the circumstances, the same bearer can be conceived as independent or dependent.

Three traits are essential in the family resemblance $\mathrm{B} / \mathrm{b}$ associated to the use of the expression être sur:

- $\left(\mathrm{B} / \mathrm{b}_{1}\right)$ The bearer contributes to support the weight of the burden

- $\left(\mathrm{B} / \mathrm{b}_{2}\right)$ The burden is in contact with the bearer

- $\left(\mathrm{B} / \mathrm{b}_{3}\right)$ The burden is above the bearer

In trait $\mathrm{B} / \mathrm{b}_{1}$, the bearer normally supports alone the weight of the burden. But it happens that a burden contributes to balance its own weight, like in the case of a fly on the ceiling. Even in this case, the bearer must contribute to maintain the position of the burden in the vertical axis: a flying fly with its back touching the ceiling is not sur but contre (against) the ceiling. The interpretation of traits $\mathrm{B} / \mathrm{b}_{2}$ and $\mathrm{B} / \mathrm{b}_{3}$ is straightforward.

11 The family resemblance $S$ is more complex. Indeed, in Vandeloise (1989), 6 traits are needed in order to describe exhaustively the use of pendre à. Because my purpose here is a comparison with the family resemblance $\mathrm{B} / \mathrm{b}$, I will only present the traits pertinent for this purpose $e^{4}$.

- $\left(\mathrm{S}_{1}\right)$ An independent bearer and/or a dependent bearer support(s) the weight of the burden

- $\left(\mathrm{S}_{2}\right)$ The burden is in contact with the independent bearer and/or the dependent bearer 
- $\left(\mathrm{S}_{3}\right)$ The burden is below the independent bearer (and the dependent bearer) ${ }^{5}$

Finally, the height dimension $(\mathrm{H})$ may take the following values:

- (h) The whole burden is higher than the bearer (and the dependent bearer)

- (h') The whole burden is lower than the independent bearer (and the dependent bearer)

- ( $h ")$ There is an intersection between the burden and the independent bearer in the vertical axis (and the burden is lower than the dependent bearer) ${ }^{7}$

- (0) None of the above conditions is met

The conditions in parentheses in ( $\left.h^{\prime}\right)$ and ( $\left.h "\right)$ only hold true if there is a dependent bearer. Values (h), ( $h$ ') and ( $h ")$ delimit clearly the meaning of the value $(0)$ in dimension $\mathrm{H}$ : there is an intersection between the burden and the independent bearer on the vertical axis and the burden is higher than the dependent bearer. As required by the definition of dimension, all the values in dimensions W, C and $\mathrm{H}$ are mutually exclusive. 


\section{The combinations determining the family resemblances $B / b, S$ and $C *$}

18 In this section, I examine all the combinations of the selected values and the spatial configurations corresponding to them. The result is admittedly very complex but this exhaustive approach is indispensable to show explicitly the intricacies hidden behind family resemblance features. Furthermore, this method enables the analyst to consider more systematically the possible usages of the linguistic forms être sur and pendre à. In this way, configurations that might escape the linguist's imagination are captured. On the other hand, this method confronts us with configurations that are contradictory, redundant or rare. I will deal in turn with these three types of configurations.

19 A combination is contradictory if it includes two values which exclude each other in all the logically possible configurations. It is obviously the case for any combination of value (w), which excludes the presence of a dependent bearer, and values $\left(c^{\prime}\right)$ and $\left(c^{\prime \prime}\right)$, which impose its existence. Such impossible or irrelevant combinations are marked in chart 1 below by the symbol ${ }^{*} \mathrm{~L}$, meaning that they are excluded for reasons internal to the structure of the family resemblance.

It may be that different combinations of values are equivalent and refer to the same set of spatial configurations. This happens for example with combinations (0ch) and (0ch'). While the former combination sanctions configurations for which a point is in contact with a line and "extends above the line", a point "extends below" the line for combination $(0 \mathrm{ch})$. However, since a point has no extension, these combinations describe equivalent configurations. When a combination describes the same configurations as another already recorded in chart 1 , it will be marked by the symbol $\mathrm{E}$, followed by the name of the equivalent combination.

21 The contradictory combinations may be excluded for reasons internal to the structure of the family resemblance. Such is not the case for the combinations corresponding to rare spatial configurations whose theoretical importance in this article is crucial. For example, the configurations corresponding to combination (woh) or to combination (woh') imply that a bearer, located above or below the burden respectively, balances directly the weight of the burden without touching it. Magnets and blowers make such configurations imaginable. They might be described by the feather is above the blower or by the iron filings are under the magnet. However, they are rare and can be described neither by être sur nor by pendre $\dot{a}^{8}$. The configurations described by the combination $(w " c h)$ are even more difficult to imagine. Here, a dependent bearer (for example a blower blowing toward the ceiling) lying on an independent bearer (for example a table) supports a burden from below without touching it. Furthermore, the burden must touch the bearer (to satisfy value $[c]$ ) without resting on it (to satisfy value [w"]). A flexible burden like a cord meets this condition. This configuration is represented in figure 5: 


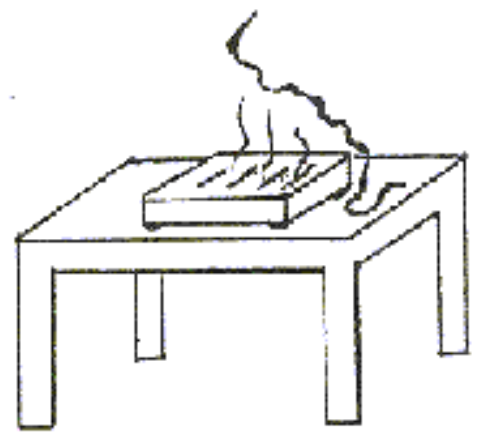

This type of monster is marked ${ }^{*} \mathrm{R}$ in chart 1 , this symbol meaning pragmatically rare. Again, this spatial configuration cannot be described by être sur or pendre $\grave{a}^{9}$. The problem for the analytical interpretation is that values ( $w "),(c)$ and (h), considered independently, are very often satisfied by the configurations in categories $\mathrm{B} / \mathrm{b}$ and $\mathrm{S}$. Therefore, configurations corresponding to combination ( $w^{\prime \prime} \mathrm{ch}$ ) cannot be analytically excluded. The rarity manifests itself only at the level of the configurations satisfying these values. This, however, can only be captured globally, while observing the configuration in figure 5 . This third type of configuration, then, provides important evidence for a global association between the spatial configurations and the words describing them.

For all the combinations that are not marked by ${ }^{*} \mathrm{~L}$ (logically impossible) or $\mathrm{E}$ (equivalent), a schema is proposed in chart 1 . One or two sentences involving être sur and/or pendre à describe these schemas. When only the former or the latter form is appropriate, the combinations belong to the extensions of the family resemblances $\mathrm{B} / \mathrm{b}$ or $\mathrm{S}$ and are marked $\left(\mathrm{B} / \mathrm{b},{ }^{*} \mathrm{~S}\right)$ or $\left({ }^{*} \mathrm{~B} / \mathrm{b}, \mathrm{S}\right)$ in the column on the right. If they can be described by both forms, they belong to both families and are marked $(B / b, S)$. Combinations that belong neither to $\mathrm{B} / \mathrm{b}$ nor to $\mathrm{S}$ are marked $\mathrm{C}^{*}$, an abbreviation for $\left({ }^{*} \mathrm{~B} /\right.$ $\left.\mathrm{b},{ }^{*} \mathrm{~s}\right)$. Finally, combinations ( $\left.w^{\prime \prime} c h\right),\left(w^{\prime \prime} c^{\prime} h "\right)$ and ( $\left.w^{\prime \prime} c^{\prime \prime} h "\right)$ are marked (?B/b, *s) because the use of etre sur to describe the corresponding configurations is questionable and (wch") is (B/b, ?S) because the use of pendre à for these configurations is difficult.

Chart 1

\begin{tabular}{|l|l|l|l|}
\hline combination & schemata & sentences & categories \\
\hline (wch) & Le livre est sur la table & The book is on the table \\
\hline (wch') & $\begin{array}{l}\text { La limaille est sur l'aimant } \\
\text { The iron fillings are on the } \\
\text { magnet }\end{array}$ & B/b, s \\
\hline
\end{tabular}




\begin{tabular}{|c|c|c|c|}
\hline & & $\begin{array}{l}\text { La goutte pend au nez } \\
\text { The drop is hanging from the } \\
\text { nose }\end{array}$ & \\
\hline (wch") & & $\begin{array}{l}\text { La limaille est sur l'aimant } \\
\text { ?La limaille pend à l'aimant } \\
\text { The iron fillings hang from the } \\
\text { magnet }\end{array}$ & $\mathrm{B} / \mathrm{b}, ? \mathrm{~s}$ \\
\hline (wc0) & E(wch") & & $\mathrm{B} / \mathrm{b}, ? \mathrm{~s}$ \\
\hline (wc'h) & $*_{\mathrm{L}}$ & & $\mathrm{B} / \mathrm{b}, ? \mathrm{~S}$ \\
\hline (wc'h') & $*_{\mathrm{L}}$ & & \\
\hline (wc'h") & $*_{\mathrm{L}}$ & & \\
\hline$\left(w c^{\prime} 0\right)$ & $*_{\mathrm{L}}$ & & \\
\hline (wc"h) & ${ }^{*} \mathrm{~L}$ & & \\
\hline (wc"h') & $*_{\mathrm{L}}$ & & \\
\hline (wc"h") & ${ }^{*} \mathrm{~L}$ & & \\
\hline (wc"0) & $*_{\mathrm{L}}$ & & \\
\hline (woh) & & $\begin{array}{l}\text { * La plume est sur la soufflerie } \\
\text { The feather is on the blowing } \\
\text { machine }\end{array}$ & $C^{*}$ \\
\hline (w0h') & & $\begin{array}{l}\text { * La limaille pend à l'aimant } \\
\text { The iron fillings hang from the } \\
\text { magnet }\end{array}$ & $C^{*}$ \\
\hline (woh") & $*_{\mathrm{R}}$ & & $C^{*}$ \\
\hline (w00) & $*_{\mathrm{R}}$ & & $\mathrm{C}^{*}$ \\
\hline
\end{tabular}




\begin{tabular}{|c|c|c|c|}
\hline (w'ch) & & $\begin{array}{l}\text { Le doigt est sur la table } \\
\text { The finger is on the table }\end{array}$ & $\mathrm{B} / \mathrm{b},{ }^{*} \mathrm{~S}$ \\
\hline (w'ch') & & $\begin{array}{l}\text { La mouche est sur le plafond } \\
\text { The fly is on the ceiling }\end{array}$ & $\mathrm{B} / \mathrm{b},{ }^{*} \mathrm{~S}$ \\
\hline (w'ch") & & La mouche est sur le mur & $\mathrm{B} / \mathrm{b},{ }^{*} \mathrm{~S}$ \\
\hline$\left(w^{\prime} c 0\right)$ & ${ }^{*} \mathrm{~L}$ & & \\
\hline (w'c'h') & & $\begin{array}{l}\text { L'acrobate est sur les échasses } \\
\text { The acrobat has long legs }\end{array}$ & $\mathrm{B} / \mathrm{b}, * \mathrm{~s}$ \\
\hline (w'c'h') & & La mouche est sur le plafond & $\mathrm{B} / \mathrm{b},{ }^{*} \mathrm{~s}$ \\
\hline (w'c'h") & & La mouche est sur le mur & $\mathrm{B} / \mathrm{b},{ }^{*} \mathrm{~s}$ \\
\hline (w'clo) & $*_{\mathrm{L}}$ & & \\
\hline (w'c"h) & & $\begin{array}{l}\text { Le soldat est sur les béquilles } \\
\text { The soldier is on the crutches }\end{array}$ & $\mathrm{B} / \mathrm{b},{ }^{*} \mathrm{~s}$ \\
\hline$\left(w^{\prime} c^{\prime \prime} h '\right)$ & קה & La mouche est sur le plafond & $\mathrm{B} / \mathrm{b},{ }^{*} \mathrm{~s}$ \\
\hline (w'c"h") & & La mouche est sur le mur & $\mathrm{B} / \mathrm{b},{ }^{*} \mathrm{~s}$ \\
\hline
\end{tabular}




\begin{tabular}{|c|c|c|c|}
\hline$\left(w^{\prime} c " 0\right)$ & $*_{\mathrm{L}}$ & & \\
\hline$\left(w^{\prime} 0 h\right)$ & 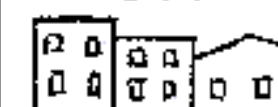 & $\begin{array}{l}\text { Le nuage est sur la ville } \\
\text { The cloud is over the city }\end{array}$ & $\mathrm{B} / \mathrm{b},{ }^{*} \mathrm{~s}$ \\
\hline$\left(w^{\prime} O h^{\prime}\right)$ & $d$ & *La mouche est sur le plafond & $C^{*}$ \\
\hline (w'Oh") & & *La mouche est sur le mur & $C^{*}$ \\
\hline$\left(w^{\prime} 00\right)$ & $\mathrm{E}\left(\mathrm{w}^{\prime} \mathrm{Oh} "\right)$ & & $C^{*}$ \\
\hline (w"ch) & ${ }^{*} \mathrm{R}$ & & $C^{*}$ \\
\hline$\left(w^{\prime \prime} \mathrm{ch}^{\prime}\right)$ & ${ }^{*} \mathrm{R}$ & & $C^{*}$ \\
\hline (w"ch") & ${ }^{*} \mathrm{R}$ & & $C^{*}$ \\
\hline (w"c0) & ${ }^{*} \mathrm{R}$ & & $C^{*}$ \\
\hline (w"c'h) & & $\begin{array}{l}\text { La Bible est sur la table } \\
\text { The Bible is on the table }\end{array}$ & $\mathrm{B} / \mathrm{b},{ }^{*} \mathrm{~s}$ \\
\hline (w"c'h') & & $\begin{array}{l}\text { La lampe pend au plafond } \\
\text { The lamp hangs from the ceiling }\end{array}$ & ${ }^{*} \mathrm{~B} / \mathrm{b}, \mathrm{S}$ \\
\hline (w"c'h") & & $\begin{array}{l}\text { Le tableau pend au mur } \\
\text { The painting is hanging from the } \\
\text { wall } \\
\text { ?Le tableau est sur le mur }{ }^{10} \\
\text { The painting is on the wall }\end{array}$ & ?B/b, S \\
\hline (w"c'0) & ${ }^{*} \mathrm{R}$ & & $C^{*}$ \\
\hline
\end{tabular}




\begin{tabular}{|c|c|c|c|}
\hline (w"c"h) & & $\begin{array}{l}\text { ?Le crayon est sur le livre } \\
\text { The pencil is on the book }\end{array}$ & $? \mathrm{~B} / \mathrm{b}, \mathrm{s}$ \\
\hline (w"c"h') & $*_{\mathrm{R}}$ & & $\mathrm{C}^{*}$ \\
\hline (w"c"h") & & $\begin{array}{l}\text { ?Le tableau est sur le mur } \\
\text { The painting is on the wall } \\
\text { Le tableau pend au mur } \\
\text { The painting hangs on the wall }\end{array}$ & ?B/b, S \\
\hline (w"c"o) & & * Le tableau pend au mur & $\mathrm{C}^{*}$ \\
\hline (w"oh) & $*_{\mathrm{R}}$ & & $C^{*}$ \\
\hline (w"oh') & $*_{\mathrm{R}}$ & & $C^{*}$ \\
\hline (w"oh") & $*_{\mathrm{R}}$ & & $c^{*}$ \\
\hline (w"00) & $*_{\mathrm{R}}$ & & $C^{*}$ \\
\hline (0ch) & & $\begin{array}{l}\text { Le point est sur la ligne } \\
\text { The dot is on the line }\end{array}$ & $\mathrm{B} / \mathrm{b},{ }^{*} \mathrm{~S}$ \\
\hline$\left(0 \mathrm{ch}^{\prime}\right)$ & $E(0 \mathrm{ch})$ & Le point est sur la ligne & $\mathrm{B} / \mathrm{b},{ }^{*} \mathrm{~S}$ \\
\hline (och") & $\mathrm{E}(0 \mathrm{ch})$ & Le point est sur la ligne & $\mathrm{B} / \mathrm{b}, * \mathrm{~S}$ \\
\hline (0c0) & $E(0 \mathrm{ch})$ & Le point est sur la ligne & $\mathrm{B} / \mathrm{b},{ }^{*} \mathrm{~S}$ \\
\hline$\left(0 c^{\prime} h\right)$ & $*_{\mathrm{L}}$ & & \\
\hline$\left(0 c^{\prime} h^{\prime}\right)$ & $*_{\mathrm{L}}$ & & \\
\hline (0c'h") & $*_{\mathrm{L}}$ & & \\
\hline$\left(0 c^{\prime} 0\right)$ & $*_{\mathrm{L}}$ & & \\
\hline (0c"h) & $*_{\mathrm{L}}$ & & \\
\hline
\end{tabular}




\begin{tabular}{|c|c|c|c|}
\hline$\left(0 c^{\prime \prime} h^{\prime}\right)$ & $*_{\mathrm{L}}$ & & \\
\hline (0c"h") & $*_{\mathrm{L}}$ & & \\
\hline (0c"0) & ${ }^{*} \mathrm{~L}$ & & \\
\hline (00h) & 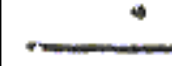 & ${ }^{*}$ Le point est sur la ligne & $\mathrm{C}^{*}$ \\
\hline (0oh') & 3 & ${ }^{*}$ Le point est sur la ligne & $\mathrm{C}^{*}$ \\
\hline (0oh") & 4 & *Le point est sur la ligne & $\mathrm{C}^{*}$ \\
\hline$(000)$ & $\mathrm{E}\left(00 \mathrm{~h}^{\prime}\right)$ & ${ }^{*}$ Le point est sur la ligne & $\mathrm{C}^{*}$ \\
\hline
\end{tabular}

The combinations sanctioning the usage of être sur and pendre à constitute the extensions of the family resemblances $\mathrm{B} / \mathrm{b}$ and $\mathrm{S}$ in French. They are listed in chart 2 with the combinations belonging to the extension of the complementary family resemblance $\mathrm{C}^{* 11}$. Combinations ${ }^{*} \mathrm{~L}$ are disregarded since they are logically excluded, for reasons that are internal to the structure of the family resemblances. Such is not the case for the important type of combinations marked * R. Symbols $W, C$ and $H$ serve as abbreviations when all the values of dimension $\mathrm{W}, \mathrm{C}$ or $\mathrm{H}$ combine with two identical values of the other dimensions. For example, (wcH) is an abbreviation for (wch), (wch'), (wch") and (wc0). Finally, for equivalent combinations, one is chosen to represent the whole group unless repeating these combinations allows for a simplification thanks to the usage of the abbreviation $\mathrm{W}, \mathrm{C}$ or $\mathrm{H}$.

Chart 2

\begin{tabular}{|l|l|l|}
\hline B $/ \mathrm{b}$ & $\mathrm{s}$ & $\mathrm{C}^{*}$ \\
\hline wcH & wch & w0H \\
\hline w'cH & ch" & w'0h' \\
\hline w'0h & s & w'0h" \\
\hline w'c'H & w"c'h" & w'00 \\
\hline w'c"H & w"c"h" & w"ch \\
\hline w"c'h & & w"c'0 \\
\hline w"c'h" & & w"c"h' \\
\hline
\end{tabular}




\begin{tabular}{|l|l|l|}
\hline w"c"h & & w"c"h' \\
\hline w"c"h" & & w"c"0 \\
\hline $0 c H$ & & w"OH \\
\hline & & $00 H$ \\
\hline
\end{tabular}

Before drawing conclusions from this chart on the structure of family resemblances and on their analytical interpretation, it is worth examining the pertinence of the values fixed in dimensions $\mathrm{W}, \mathrm{C}$ and $\mathrm{H}$. One value is pertinent if there are at least two combinations which differ only by this value and belong to different family resemblances. For example, $\left(w^{\prime \prime} c^{\prime} h\right)$ and $\left(w^{\prime \prime} c^{\prime} h '\right)$, sanctioning respectively the use of sur in la Bible est sur la table (a configuration of category $\mathrm{B} / \mathrm{b}$ ) and of pendre à in la lampe pend au plafond (a configuration of category S), establish the necessity of distinguishing value (h) from value ( $h ')$. These combinations, then, may be compared to the minimal pairs establishing the inventory of the phonemes in a language. Ideally, each combination should sanction either the use of sur or the use of pendre à but not the use of both expressions. Furthermore, all the configurations in the world corresponding to one combination should be linguistically described in the same way. There are only 3 minor exceptions to this ideal discrimination. I consider them in turn.

(a) A first exception is combination (wch'), characterizing configurations that can be described by la limaille est sur l'aimant as well as configurations described by la goutte pend au nez, for which être sur would be inappropriate. Note however that, in contrast to the iron filings on the magnet, the balance of the drop hanging from the nose is unstable. In Vandeloise (1989), a further trait of the family resemblance $S^{12}$ specifies that the burden in the relationship $\mathrm{S}$ must be somewhat mobile, a condition fitting better the drop than the iron fillings. Thus, had some features of the relationship $\mathrm{S}$ not been disregarded for the sake of comparison, the distinction between these two configurations would have been established. This exception, then, can be blamed on the simplification of family resemblance S. A same explanation can be given for combination ( $w " c " h ")$ which sanction the use of ?le tableau est sur le mur (a configuration belonging to the category $\mathrm{B} / \mathrm{b}$ ) as well as the use of le tableau pend au mur (a configuration belonging to the category S). Here also, the choice of the latter sentence is facilitated by the leeway between the picture and the wall. As indicated by the question mark, the use of le tableau est sur le mur is questionable. Le tableau est au mur is normally preferred in this circumstance.

(b) Combination ( $\left.w^{\prime \prime} c ' h\right)$ constitutes a second exception. Indeed, être sur cannot be used for all the spatial relationships satisfying these values. For example, figure 6 may be described by sentence (1) but sentence (2) cannot describe figure 7, even though this spatial configuration satisfies all the values in combination $\left(w^{\prime \prime} c^{\prime} h\right)^{13}$ : 


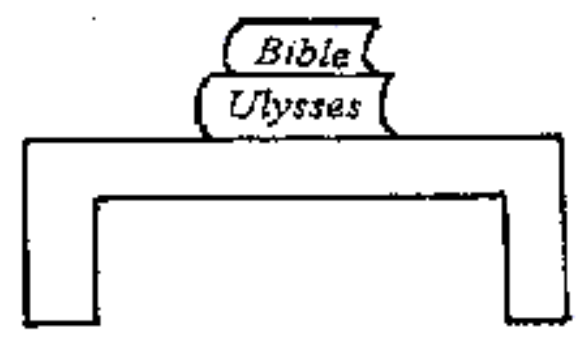

Figure 7

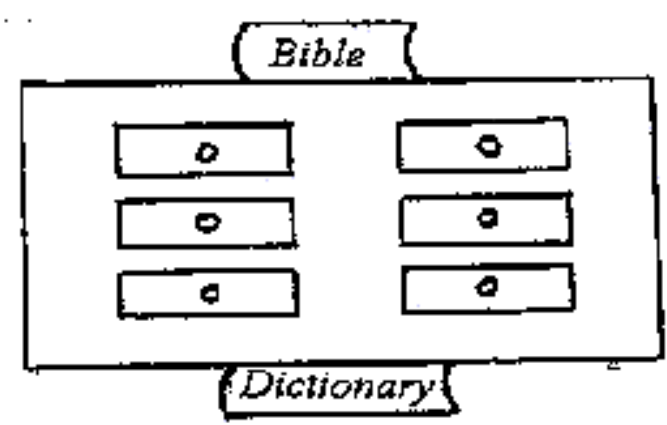

(1) La bible est sur Ulysses

The Bible is on Ulysses

(2) *La bible est sur le dictionnaire

The Bible is on the dictionary

This may be explained because the dependent bearer involved in values ( $\left.w^{\prime \prime}\right)$ and ( $\left.c^{\prime}\right)$ can only be tolerated if small enough to play a negligible role in the conceptualization of the configuration. Such is the case for Ulysses between the Bible and the table in figure 6 but not for the desk between the Bible and the dictionary in figure 7. Thus, combination ( $w^{\prime \prime} c^{\prime} h$ ) associates configurations that can be described by etre sur (figure 6) with configurations for which this use is impossible (figure 7). In order to explain this contrast, one might specify the nature of dependent bearer in support: they can only be tolerated if their role in the conceptualization of the situation is considered negligible. But this constraint cannot be introduced in the values in dimensions $\mathrm{W}, \mathrm{C}$ and $\mathrm{H}$ because configurations described by pendre à may admit very conspicuous dependent bearers.

(c) Some burden located above the bearer without contact with it constitutes the last exception. The configurations described by the four sentences below fit values (w'oh) since the clouds and the birds support their weight, are not in contact with the city and are higher than it. They are listed in order of decreasing acceptability:

(3) Les nuages sont sur la ville

The clouds are over the city

(4)Les oiseaux volent sur la ville

The birds fly over the city

(5) ?Les oiseaux sont sur la ville

The birds are over the city

(6) *Un oiseau est sur la ville

One bird is over the city

Unlike the usual figure/ground alignment (Talmy 1983) in which the figure is smaller than the ground, these usages are more appropriate when the figure is as big as the 
ground and covers it. Because the movement involved in sentence (4) enables a better covering of the city by the birds than in the static configuration described by sentence (5), the former sentence is more acceptable than the latter. Thus, a further explanation must be found to justify these usages of preposition sur, as far removed as possible from the relationship bearer/burden, which usually triggers the choice of this preposition. This phenomenon apparently bears some resemblance to some uses of the English preposition over (Dewell 1994). Be that as it may, the unacceptability of sentence (6) shows that the combination of values ( $w^{\prime} 0 \mathrm{~h}$ ) does not constitute a sufficient condition to justify the use of the preposition sur.

\section{The role of category validity in the structure of family resemblances $B / b$ and $S$}

31 The three above minor exceptions notwithstanding, chart 1 and chart 2 provide an adequate description of the uses of the linguistic forms être sur and pendre à. The family resemblances $\mathrm{B} / \mathrm{b}$ and $\mathrm{S}$ do not describe classical categories. In particular, no value is a necessary condition in family resemblance $\mathrm{B} / \mathrm{b}$ since none is present in all the combinations of this family. Furthermore, since all of the values in family resemblance B/ $\mathrm{b}$ are in family resemblance $\mathrm{S}$ or $\mathrm{C}^{*}$ as well, none of them is sufficient. Family resemblance $\mathrm{S}$ is better delimited than family resemblance $\mathrm{B} / \mathrm{b}$. Notably, the use of pendre à is prevented by values $\left(\mathrm{w}^{\prime}\right)$ and $(0)$ of dimension $\mathrm{W}$ and values $(\mathrm{h})$ and $(0)$ of dimension $\mathrm{H}$. Nevertheless, no value is a necessary condition for $\mathrm{S}$ since this family resemblance admits 2 values in each dimension. They are not sufficient either since each of them appears in family resemblance $B / b$.

An analytical interpretation has to determine the family resemblance that each spatial configurations belongs to by considering each value independently of the other values in the family resemblances that it is competing with. Weights and categorization validity have been conceived in cognitive psychology for this purpose. Indeed, because some values are common to several family resemblances, their role in each family must be differentiated by a weight, proportional to the probability of its appearances in this family resemblance and inversely proportional to the probability of its appearances in all the family resemblances. Thus, the weight in family resemblance $R_{j}$ of a value $V_{k}$ appearing in family resemblances $R_{1}-R_{m}$ is:

$$
\text { Weight } \cdot\left(V_{k} \cdot R_{i j}\right) \cdot=\frac{\operatorname{Pr}\left(V_{k}, R_{j}\right)}{\operatorname{Pr}\left(V_{k}, R_{1}\right)+\operatorname{Pr}\left(V_{k}, R_{2}\right)+\ldots+\operatorname{Pr}\left(V_{k}, R_{n}\right)}
$$

The weight of a constituent varies from 0 to 1 . The categorization validity for a combination in a family resemblance is the sum of the weights of its values.

As an example, I will present an experiment conducted by Rosch et al. (1976) with two artificial family resemblances. With her colleagues, she trained subjects to recognize the groups in two artificial categories (A) and (B). Each category is constituted by 6 groups of five letters and numbers:

\begin{tabular}{|l|l|}
\hline (A) & (B) \\
\hline HPNWD & JXPHM \\
\hline
\end{tabular}




\begin{tabular}{|l|l|}
\hline HPNSJ & XPHMQ \\
\hline GKNTJ & PHMQB \\
\hline 4KCTG & HMQBL \\
\hline 4KC6D & MQBLF \\
\hline HPC6B & QBLFS \\
\hline
\end{tabular}

None of the letters is a necessary or sufficient condition for membership in a category and some letters like $H$ appear in both categories. Nevertheless, categories (A) and (B) were constructed in such a way that subjects were able to memorize them. Indeed, each group of letters and numbers may be attributed an index of representativity in each category, determined by the sum of the appearances of its constituents in the family. ${ }^{14}$ Each group in category (A) was recognized by the subjects because it has a higher index in this category than in category (B) and vice versa. Rosch et al. noticed that the representativity of each element in a family resemblance (determined by the ease of recall) was proportional to its index in the family resemblance. These indices make an analytical interpretation of artificial family resemblances possible.

If one looks at the combinations of family resemblances $\mathrm{B} / \mathrm{b}, \mathrm{S}$ and $\mathrm{C}^{*}$ in chart 2 , they superficially look like the letters and integers in artificial family resemblances (A) and (B). Therefore, one might think that the same calculation is applicable to the values in these combinations. But the family resemblances $\mathrm{B} / \mathrm{b}$ and $\mathrm{S}$, delimiting the natural categories of support and suspension, cannot be analyzed in the same way as artificial categories (A) and (B). Indeed, in Rosch's artificial family resemblances, constituents of the combinations (letters or integers stand for themselves) and values coincide. Such is not the case with family resemblances $\mathrm{B} / \mathrm{b}$ and $\mathrm{S}$ since each combination of values represents a set of spatial configurations of support and suspension in the world satisfying these values. In this case, the number of occurrences of each value in the combinations belonging to family resemblances $\mathrm{B} / \mathrm{b}, \mathrm{S}$ and $\mathrm{C}^{*}$ does not reflect the importance of these values. Indeed, the number of configurations in the world satisfying each combination varies dramatically from combinations such as (wch) (which represents prototypical support and, as a consequence, a huge set of spatial configurations) to the set of combinations marked ${ }^{*} R$ (which represent only a few exceptional configurations). Since these discrepancies strongly influence the acquisition of être sur and pendre à, categories $\mathrm{B} / \mathrm{b}$ and $\mathrm{S}$ cannot be characterized simply by the number of appearances of each value in the combinations of family resemblances $\mathrm{B} / \mathrm{b}$ and $\mathrm{S}$. Instead, the probabilities involved in the calculus of the weight of value $w$ in the family resemblance $\mathrm{B} / \mathrm{b}$ corresponds to:

$$
\operatorname{Pr}(w ; B / b)=\frac{\text { Number of configurat ions in category } B / b \text { satisfying value } w}{\text { Number of configurat ions in category } B / b}
$$

$\operatorname{Pr}(\mathrm{w}, \mathrm{B} / \mathrm{b})$ must not be confused with the probability of appearances of the letter $w$ in the combinations of family resemblance $\mathrm{B} / \mathrm{b}$, as it is the case in Rosch's artificial family resemblances.

Shifting from the number of occurrences of a value in the combinations belonging to a family resemblance to the number of spatial configurations it represents in the world is 
very difficult. Indeed, since these numbers can only be intuitively evaluated, the objectivity sought in the calculation of category validity is diminished. There are further difficulties with the calculation of category validity for natural categories. First, family resemblances differ in complexity, that is, in the number of traits or values which constitute them. Remember that the family resemblance $S$ should involve six traits. Therefore, it is more complex than the family resemblance $\mathrm{B} / \mathrm{b}$, characterized by 3 traits. If all the traits of family resemblance $\mathrm{S}$ were taken into consideration, the largest possible category validity in this family resemblance would exceed the largest possible category validity in the family resemblance $\mathrm{B} / \mathrm{b}$. In this article, I get around the difficulty by limiting the comparison to traits $\mathrm{B} / \mathrm{b}_{1}-\mathrm{B} / \mathrm{b}_{3}$ in family resemblance $\mathrm{B} / \mathrm{b}$ and $\mathrm{S}_{1}-\mathrm{S}_{3}$ in family resemblance $S$. Even though this approximation may be tolerated, it appears once again that the calculation of categorization validity for the family resemblances $\mathrm{B} / \mathrm{b}$ and $\mathrm{S}$ cannot be carried out with a high degree of precision. A second problem concerns the manipulations necessary in order to make the values of the family resemblances comparable. This task can introduce secondary factors in the description of a family resemblance in order to facilitate the comparison with another family resemblance. A case in point in this article are dependent bearers, introduced in the description of the linguistic form etre sur, for which their role is marginal, because they are very important in the description of the linguistic form pendre à. A final problem lies in the large number of family resemblances in which the probability of a pervasive value must be calculated in order to evaluate its weight in one family resemblance. Contact represented in dimension C, for example, is involved in the description of almost all the spatial relationships. This proliferation does not appear in this article because our attention is conveniently focused on the three categories $\mathrm{B} / \mathrm{b}, \mathrm{S}$ and $\mathrm{C}^{*}$ only.

\section{Application of the analytical interpretation to the family resemblances $B / b, S$ and $C$ *}

The analytical interpretation of family resemblances will succeed to delimit the combinations belonging to family resemblances $\mathrm{B} / \mathrm{b}$ and $\mathrm{S}$ through all the combinations of values in dimensions $\mathrm{W}, \mathrm{C}$ and $\mathrm{H}$ (except those marked ${ }^{*} \mathrm{~L}$ and $\mathrm{E}$ ) only if the category validity of these values meets the four following conditions:

- $\left(C_{1}\right)$ Any time a combination belongs to family resemblance $\mathrm{B} / \mathrm{b}$ or $\mathrm{S}$, its category validity in this family resemblance is superior to its category validity in the other family resemblance.

- $\left(\mathrm{C}_{2}\right)$ Any time a combination belongs to both family resemblances $\mathrm{B} / \mathrm{b}$ and $\mathrm{S}$, its category validity in the two family resemblances is approximately equal.

- $\left(\mathrm{C}_{3}\right)$ Any time a combination belongs to another family resemblance than $\mathrm{B} / \mathrm{b}, \mathrm{S}$ and $\mathrm{C}^{*}$, its category validity in this family resemblance is superior to its category validity in family resemblances $\mathrm{B} / \mathrm{b}$ and $\mathrm{S}$.

- $\left(C_{4}\right)$ No combination in another family resemblance than $B / b, S$ and $C^{*}$ has a category validity in family resemblance $\mathrm{B} / \mathrm{b}$ and $\mathrm{S}$ higher than the category validity of any other combination in these family resemblances.

The conditions $\mathrm{C}_{1}-\mathrm{C}_{4}$ have been informally tested. The evaluation of the probabilities was of course very approximate. However, in testing conditions $\mathrm{C}_{1}-\mathrm{C}_{4}$, I made myself the devil's advocate and used the leeway given in the evaluation of the probabilities to favor as much as possible the analytical interpretation whose adequacy is questioned in this article. 
41 (a) For a matter of convenience, the category validity is first tested for the combinations which belong both to family resemblance $\mathrm{B} / \mathrm{b}$ and to family resemblance $\mathrm{S}$. Condition 2 is met if the indices of representativity in each family resemblance are approximately equal. Since the spontaneous estimations did not yield the desired results, probabilities were adjusted in order to meet condition 1. However, whenever a value was spontaneously judged superior to another, I did refrain from reversing their order. Indeed, judgements on the relative weight of values are those that can be most trusted.

(b) In the following step, the adjusted weights are used in order to test condition 1. Once again, weights were modified in order to improve the results, but without reversing the relative order of probability.

(c) Condition 3 is tested with the revised weights. The results were far from satisfying this condition. Indeed, any new modification of the probabilities improving this condition did at the same time jeopardize the appropriateness of categorization validity for conditions 1 and 2. Consequently, categorization validity proved unable to establish the boundaries between family resemblances $\mathrm{B} / \mathrm{b}, \mathrm{S}$ and $\mathrm{C}^{*}$.

(d) The failure of categorization validity to meet condition 3 might be blamed on the peculiar nature of category $\mathrm{C}^{*}$, the complement of categories $\mathrm{B} / \mathrm{b}$ and $\mathrm{S}$, which might break down in many lexical categories. Condition 4 , however, is a reasonable requirement imposed on each member of category $C^{*}$ in isolation. Indeed, if a $C^{*}$ combination has a higher categorization validity in family resemblance $\mathrm{B} / \mathrm{b}$ or $\mathrm{S}$ than some other combinations in these family resemblances, why should this combination be excluded from these family resemblances? However, calculations demonstrate that many combinations in $\mathrm{C}^{*}$ get a higher index in family resemblances $\mathrm{B} / \mathrm{b}$ and $\mathrm{S}$ than some combinations in these family resemblances.

The conclusion of this informal demonstration is that one cannot circumscribe the subset of combinations belonging to family resemblances $\mathrm{B} / \mathrm{b}, \mathrm{S}$ and $\mathrm{C}^{*}$ only by considering intrinsic categorization validity attributed to each value independently of the other values. Therefore, probabilities and category validity cannot salvage the analytical interpretation of family.

\section{Conclusions}

Two interpretations of family resemblances $\mathrm{B} / \mathrm{b}$ and $\mathrm{S}$, representing the spatial configurations conveyed by être sur and pendre à in French, are compared in this article. According to the analytical interpretation of family resemblances, their traits or values considered in isolation should determine these lexical categories. This goal would be easier to reach if être sur and pendre à were sanctioned by all the combinations of values involved in family resemblances $\mathrm{B} / \mathrm{b}$ and $\mathrm{S}$. However, as demonstrated in chart 2 of section 2-a direct result of the investigation in chart 1-, only a subset of these combinations correspond to configurations described by these expressions. The delimitation of these subsets is complicated by the fact that the family resemblances $\mathrm{B} / \mathrm{b}$, $\mathrm{S}$ and their complement $\mathrm{C}^{*}$ share several values. Therefore, in order to determine which combination belongs to which family resemblance, the values must be given different indices in each family resemblance. Category validity, used in cognitive psychology to investigate the structure of family resemblances have been tested without success in section 4 of this article. Thus, a probabilistic approach cannot help to analytically 
delineate the appropriate subsets of combinations sanctioning the use of être sur and pendre à.

According to the analytical interpretation of family resemblance, speakers would choose lexical expressions at the level of values rather than at the global level of spatial configurations. As a consequence, the linguistic forms être sur and pendre à would be used without hesitation any time traits or values with a high category validity in family resemblances $\mathrm{B} / \mathrm{b}, \mathrm{S}$ or $\mathrm{C}^{*}$ combine in a pragmatically rare spatial configuration. This would be the case for the exceptional configuration in figure 5. Indeed, it is represented by combination ( $\left.w^{\prime \prime c h}\right)$ and, taken in isolation, values ( $w^{\prime \prime)}$, (c) and (h) frequently appear when the linguistic forms être sur and pendre à are utilized. However, speakers refrain from using these expressions for such pragmatically rare spatial configurations. This provides further empirical evidence against the analytical interpretation of family resemblances. Therefore, linguistic decisions are not triggered by simple features, be they organized in the rigid pattern of classical categories or in the looser structure of family resemblances. As useful as traits and values may be for the linguist in describing the use of être sur or pendre à for a spatial configuration, they are not used by the speaker independently of what other traits or values may or may not be possessed by this configuration

This conclusion leads to a global interpretation of family resemblances. A first alternative would be to memorize all the combinations corresponding to the use of etre sur and pendre à. A machine provided with the list of these combinations constituting family resemblances $\mathrm{B} / \mathrm{b}$ or $\mathrm{S}$ could use être sur and pendre à properly if it were able to recognize the values satisfied by each spatial configuration ${ }^{15}$. Humans can certainly execute the second part of this program, but it is unlikely that their knowledge of these lexical categories corresponds to a memorization of the combinations of family resemblances $\mathrm{B} / \mathrm{b}$ and $\mathrm{S}^{16}$. Another alternative is provided by the structure of family resemblances $\mathrm{B} / \mathrm{b}$ and $\mathrm{S}$ represented in figure 2 of the introduction. The core of prototypical spatial configurations that share all the traits of the family resemblance is likely to play an important role in the cohesion of these lexical categories. Therefore, the prototypical spatial configurations of support and suspension we are exposed to might play an important role in our knowledge of être sur and pendre $\grave{a}^{17}$.

\section{BIBLIOGRAPHY}

Bierwisch, Manfred (1967). « Some semantics universals of German adjectivals », Foundations of Language 3. 1-36

Bloom Paul, Mary A. Peterson, Lynn Nadel \& Merill F. Garrett (eds.). (1996). Language and Space. Cambridge, MA: The MIT Press

Bowerman, Melissa (1996)a. « The origins of children's spatial semantic categories: cognitive versus linguistic determinants », in: John J. Gumperz \& Stephen C. Levinson (eds.), 145-176 
Bowerman, Melissa (1996)b « Learning how to structure Space for Language », in: Paul Bloom, Mary A. Peterson, Lynn Nadel \& Merill F. Garrett (eds.), 383-435

Clark, Eve (1973). « Non-linguistic strategies and the acquisition of word meanings », Cognition 2: $161-182$

Dewell Robert B. (1994). « Over again: Image-schema transformations in semantic analysis », Cognitive Linguistics 5-4: 351-380

Estes, William K. (1983) «Categorization, Perception and Learning », in Perception, Cognition and Development, Thomas J. Tighe \& Bryan E. Schepp (eds.)

Garner, W. R. (1978). « Aspects of a stimulus: Features, Dimensions and Configurations », in: Eleanor Rosch \& Lloydt (eds.), 99-134

Hampton, James A. (1995). « Testing the prototype theory of concepts », Journal of memory and language $34,686-708$

Kemler Nelson, G. Deborah (1990). « When experimental findings conflict with everyday observations: reflections on children's category learning », Child Development 61: 606-610 Kleiber, George1(990). La Semantique des Prototypes. Paris: Presses Universitaires de France Langacker, Ronald W. (1986). Foundations of Cognitive Grammar, vol. 1. Stanford: Stanford University Press

Levinson, Stephen C. (1996). « Relativity in spatial conception and description », in: Gumperz John J. \& Stephen C. Levinson (eds.), 177-202

Mandler, Jean M. 1(992). « How to build a baby: II Conceptual primitives », Psychological Review 99: 587-604

Mandler, Jean M. (1996). « Preverbal Representation of Language », in: Paul Bloom, Mary A. Peterson, Lynn Nadel \& Merill F. Garrett (eds.), 365-382

Medin, Douglas L. \& Schaffer, M. M (1978). « Context theory in classification learning », Psychological review 85, 207-238

Medin, Douglas L. (1983). «Structural Principles in Categorization" » in Perception, Cognition and Development, Thomas J. Tighe \& Bryan E. Schepp (eds.)

Murphy Gregory L. (1982). «Cue Validity and Levels of Categorization », Psychological Bulletin 9, 174-177

Pick, Herbert \& Linda Acredolo (eds.) (1983). Spatial Orientation: Theory, Research and Applications. New York: Plenum Press

Rosch \& Lloyd (eds.) (1978). Cognition and Categorization. Hillsdale, N.J.: Lawrence Erlbaum

Rosch Eleanor \& Carolyn Mervis (1975). « Family Resemblances: Studies in the Internal Structure of Categories », Cognitive Psychology 7: 573-605

Rosch Eleanor, C. Simpson \& R. S. Miller (1976). «Structural Bases of Typicallity Effects », Journal of Experimental Psychology: Human Perception and Performance 2: 491-502

Sebeok A. Thomas \& Jean Umiker-Sebeok (eds.) (1995). Advances in Visual Semiotics: The Semiotic Web 1992-1993. Berlin: Mouton de Gruyter

Talmy Leonard (1983). « How Language Structures Space », in: Herbert Pick \& Linda Acredolo (eds.), 225-282 
Thomas J. Tighe \& Bryan E. Schepp (eds.) (1983) Perception, Cognition and Development, Hillsdale: Laurence Erlbaum Associates Tsohatzidis, Savas (ed.)

Thomas J. Tighe \& Bryan E. Schepp (eds.) (1990). Meanings and Prototypes: Studies in Linguistic Categorization. London \& New York: Routledge

Vandeloise, Claude (1990)a. «L'expression linguistique de la suspension », Les Cahiers de Lexicologie: $111-148$

Vandeloise, Claude (1990)b « Representation, Prototypes and Centralit », in: Savas Tsohatzidis (ed.), 403-437

Vandeloise, Claude (1991). Spatial prepositions: A case study in French. Chicago: The University of Chicago Press

Vandeloise, Claude (1994). « Methodology and Analyses of the preposition in », Cognitive Linguistics 5-2: 157-185

Vandeloise, Claude (1995). « Cognitive Linguistics and Prototypes », in: Thomas A. Sebeok \& Jean Umiker-Sebeok, 423-442

Vandeloise, Claude (2001). « Plus de clarté sur la relation porteur/porté », in: Mélanges Liliane Tasmowsky.

Ward B. Thomas, Edward Vela \& Sally Duffin Hass (1990). « Children and Adults learn familyresemblance categories analytically », Child Development 61: 593-605

Wierzbicka, Anna (1990). « The meaning of color terms », Cognitive Linguistics 1: 99-149

Wittgenstein, Ludwig (1953). Philosophical Investigations, New York: Macmillan

Younger, Barbara (1992). « Developmental Change in Infant Categorization: The Perception of correlations among Facial Features », Child Development 63:1526-1535

\section{NOTES}

1. By 'spatial configuration', I mean the position in space of an object relative to another object.

2. According to the interpretation of family resemblances proposed in figure 1 , this means that family resemblances $\mathrm{B} / \mathrm{b}$ and $\mathrm{S}$ might collapse in one single family resemblance.

3. In psychology, using a set of schematized faces as experimental data, Ward and al. (1990) also claim that children and adults learn family resemblance categories analytically, by fixing their attention on one attribute. By contrast, Kemler Nelson (1990) believes that the acquisition of family resemblances is more holistic.

4. Shortcomings of this simplification are discussed in section 3.

5. The three additional traits of the family resemblance $S$ are:

- $\left(\mathrm{S}_{4}\right)$ One of the places of connection between the burden, the dependent bearer and the independent bearer is a point; the place of connection between the burden and the bearers can be linear

- $\left(\mathrm{S}_{5}\right)$ The points of application of the forces supporting the constituent elements are located on the same vertical axis

- $\left(\mathrm{S}_{6}\right)$ The burden and the dependent bearer are free to move in any non-vertical directions .

6. The part of the burden above the independent bearer and/or the free extremity of the dependent bearer as well as the part of the dependent bearer above the bearer are negligible. 
7. Like trait $\mathrm{S}_{3}$, values $\mathrm{h}^{\prime}$ and $\mathrm{h}^{\prime}$ are oversimplified.

8. The preposition sur may be used if the auxiliary être is replaced by a full verb and if additional material describing the situation is adduced as in: La plume reste sur la soufflerie grâce à l'air qui souffle

9. Once again, with further lexical material, as in la corde est sur la table, soutenue par l'air qui souffle , sur can contribute to the description of the configuration in figure 5. The point is that the preposition sur cannot describe alone the situation with the auxiliary etre.

10. With vertical bearers, the acceptability of être sur decreases with the autonomy and the weight of the burden. Whereas la tache est sur le mur (the spot is on the wall) is perfect, le chauffeeau est sur le mur (the boiler is on the wall) is odd. A poster would certainly be on the wall but a painting is a borderline case. One would rather say le tableau est au mur.

11. For reasons of exposition, I found it easier to deal with the complement of both categories $B /$ $\mathrm{b}$ and $\mathrm{S}$ rather than dealing separately with the complement of $\mathrm{B} / \mathrm{b}$ and the complement of $\mathrm{S}$.

12. Trait $\mathrm{S}_{6}$ in footnote 3

13. The Bible and the desk are on the dictionary, but in this case the dictionary is a bearer in direct contact with a complex burden, composed of the Bible and the desk.

14. 14For example, the index of HPNWD in the category (A) is $3+3+3+1+2=12$ and its index in the category (B) is $4+3+0+0+0=7$.

15. From the point of view of artificial intelligence, then, this type of analysis might turn out to be useful

16. Looking at chart 2 , one may wonder why a language would put combinations ( $w^{\prime} \mathrm{ch}$ ) and ( $w^{\prime} c h '$ ) in family resemblance B/b while associating combination (wch') with family resemblance S. Unless languages are considered as completely arbitrary structures, why should they shelter such unlikely associations?

17. This conclusion is in keeping with the exemplar view of categories according to which categorization is made on the basis of specific item information or to the context model (Medin and Schaffer 1978) in which "an instance to be classified acts as a retrieval cue to access information associated with similar stored exemplars" (Medin, 1983).

\section{ABSTRACTS}

This article investigates the strength and the shortcomings of the notion of family resemblance features in the description of the linguistic representation of spatial relationships. The relationship bearer/burden $(\mathrm{B} / \mathrm{b})$ conveyed in French by $x$ est sur $y$ and the relationship of suspension (S) conveyed by $x$ pend à $y$ are taken as examples. The relationships $\mathrm{B} / \mathrm{b}$ and $\mathrm{S}$ will be described by traits or values determining how the bearer support the burden (dimension $\mathrm{W}$ ); the type of contact between the bearer and the burden (dimension C); and the relative positions of the bearer and the burden in the vertical axis (dimension $\mathrm{H}$ ). Each situation in the world described by $x$ est sur $y$ or $x$ pend à $y$ may be represented by a combinations of three values in dimensions $\mathrm{W}, \mathrm{C}$ and $\mathrm{H}$. I call the sets of these combinations the family resemblance $\mathrm{B} / \mathrm{b}$ and the family resemblance $S$. According to a first interpretation of these family resemblances, the sets of combinations of family resemblances $\mathrm{B} / \mathrm{b}$ and $\mathrm{S}$ might be delineated by considering their values in isolation, independently of the global situations they characterize. In order to reach this goal, probabilistic approaches attribute individual category validity to values. If this 
analytical interpretation of family resemblances were true, family resemblances might be considered as the last shelter for the semantic features of structuralist linguistics. This article demonstrates the shortcomings of the analytical interpretation of family resemblances: even though, linguistically, they allow for an exhaustive description of the expressions être sur and pendre $\grave{a}$, it is unlikely that, psychologically, categories $\mathrm{B} / \mathrm{b}$ and $\mathrm{S}$ cannot be completely delimitated by an additive summation of the values in family resemblances $\mathrm{B} / \mathrm{b}$ and $\mathrm{S}$. According to a second interpretation of family resemblances $\mathrm{B} / \mathrm{b}$ and $\mathrm{S}$, speakers pay attention to the overall similarity of situations. In this global interpretation of family resemblances, values are treated in a non-independent way. This knowledge is solidly anchored in the experience of the world.

Les avantages et les inconvénients des traits dans les ressemblances de famille qui décrivent les relations spatiales sont évalués dans cet article. La relation porteur/porté $(\mathrm{P} / \mathrm{p})$, décrite par $x$ est sur $y$, et la relation de suspension (S), décrite par $x$ pend à $y$, sont choisies comme exemples. Les relations $\mathrm{P} / \mathrm{p}$ et $\mathrm{S}$ sont décrites par des traits ou des valeurs qui déterminent comment le porteur supporte le porté (dimension W) ; le type de contact entre le porteur et le porté ( dimension $\mathrm{C}$ ) ; et la position relative du porteur et du porté sur l'axe vertical (dimension $\mathrm{H}$ ). Chaque situation dans le monde qui est décrite par $x$ est sur $y$ ou par $x$ pend à $y$ peut être caractérisée par une combinaison de trois valeurs des dimensions $\mathrm{W}, \mathrm{C}$ et $\mathrm{H}$. Ces ensembles de combinaisons sont appelés famille de ressemblance $\mathrm{P} / \mathrm{p}$ et famille de ressemblance $\mathrm{S}$. Selon une première interprétation de ces familles de ressemblances, les ensembles de combinaisons qui les déterminent seraient délimités en considérant isolément chaque valeur, indépendamment de la situation globale qu'elles représentent. Pour atteindre ce but, des approches basées sur les probabilités attribuent différents index de représentativité à chaque valeur dans chaque catégorie. Si cette interprétation analytique s'avérait exacte, les familles de ressemblance constitueraient un dernier refuge pour les traits sémantiques de la linguistique structuraliste. L'article démontre l'échec de l'interprétation analytique des ressemblances de famille. Bien que, linguistiquement, elle permette une description exhaustive des expressions être sur et pendre à, il est peu plausible que, psychologiquement, les catégories $\mathrm{P} / \mathrm{p}$ et $\mathrm{S}$ soient complètement déterminées en additionnant isolément les poids des valeurs des combinaisons. Selon une seconde interprétation des familles de ressemblance $\mathrm{P} / \mathrm{p}$ et $\mathrm{S}$, les locuteurs se basent sur une reconnaissance globale des similarités entre les situations décrites par être sur et pendre à. Dans cette interprétation globale des ressemblances de famille $\mathrm{P} / \mathrm{p}$ et $\mathrm{S}$, les valeurs ne sont pas traitées indépendamment et la maîtrise de ces catégories dépend étroitement de notre expérience du monde.

\section{INDEX}

Keywords: category validity, dimension, family resemblance, index of representativity, pendre à, semantic feature, trait, sur, value, weight

\section{AUTHOR}

\section{CLAUDE VANDELOISE}

Louisiana State University, USA 